| Volume-1 | Issue-1| Jun-Jul -2019 |

Short Communication

\title{
Medicinal and Therapeutic Value of Sesbania grandiflora
}

\author{
Abdul Kader Mohiuddin* \\ Bangladesh

\section{*Corresponding Author} \\ Abdul Kader Mohiuddin

\section{Article History} \\ Received: 02.07.2019 \\ Accepted: 17.07.2019 \\ Published: 30.07 .2019
}

Assistant Professor, Department of Pharmacy, World University of Bangladesh, 151/8, Green Road, Dhanmondi, Dhaka - 1205,

\begin{abstract}
There are around 60 global species belonging to the genus Sesbania which are commonly found to be grown in Africa, Australia, and Asia. The leaves of Sesbania grandiflora have been used in local traditional medicine since ancient times. Major chemical constituents are alkaloids, flavonoids, glycosides, tannin, anthraquinone, steroid, pholobatannins, and terpenoids. Isovestitol, medicarpin, sativan (isoflavonoids) and betulinic acid (tannin substance) are the major constituents responsible for antibacterial and antifungal, antioxidant, anti-urolithiatic, anticonvulsant and anxiolytic, and hepatoprotective properties. Also, the plant extract contains alkaloids, phenolics, tannins, triterpenoids, and sterols. All parts of S. grandiflora are used in traditional medicine and phytochemical investigations have been conducted on extracts of the leaves, seeds and roots of S. grandiflora to provide scientific validation of its properties.
\end{abstract}

Keywords: Sesbania grandiflora; isoflavonoids; Heron flower; traditional medicine; Bengali cuisine

\section{Short Communication}

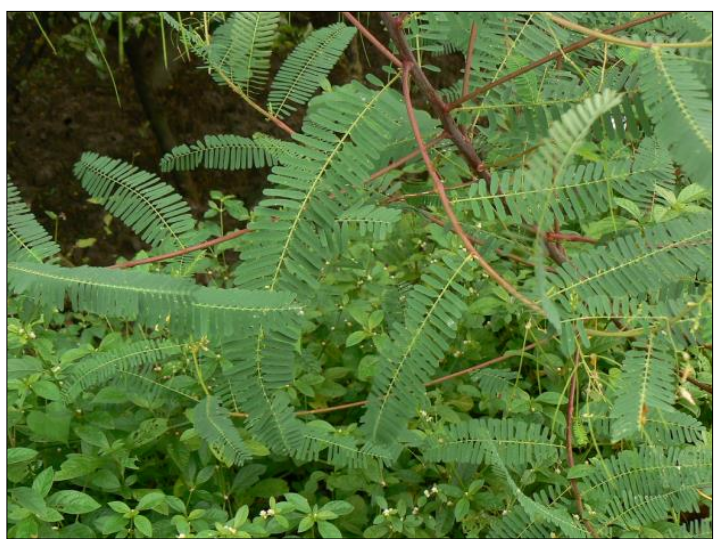

Fig-1: Top View of Sesbania grandiflora [1].

Native to tropical Asia, commonly known as vegetable hummingbird, agati or hummingbird tree, is a small tree in the genus Sesbania. It is a short-lived, soft-wooded, loosely-branching tree with a rather open crown; it can grow 8 - 15 meters tall.

Copyright @ 2019: This is an open-access article distributed under the terms of the Creative Commons Attribution license which permits unrestricted use, distribution, and reproduction in any medium for non commercial use (NonCommercial, or CC-BY-NC) provided the original author and source are credited. 


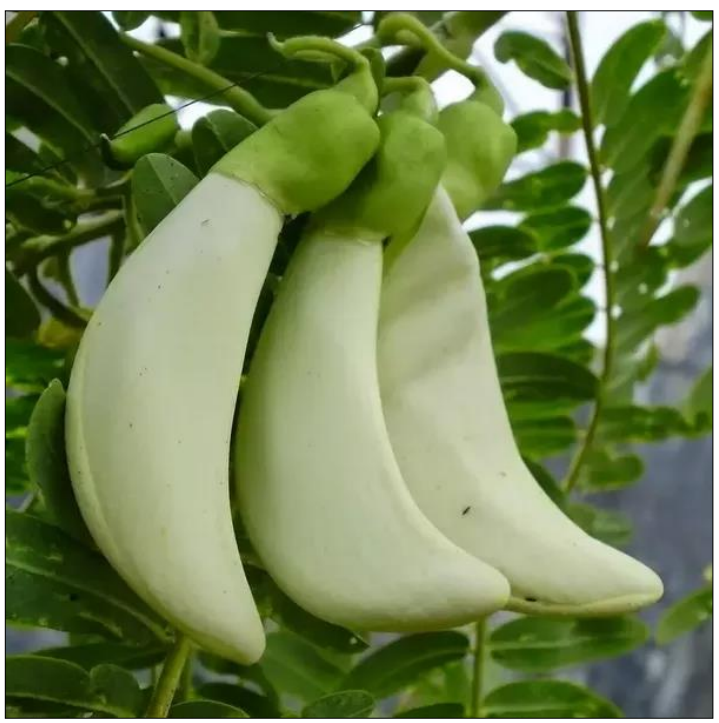

Fig-2: Bok phool or Heron flower [2].

The Sesbania gradiflora or the humming bird tree bears a big white flower that is heartily used in Bengali cuisine. white flower variety of $\mathrm{S}$. grandiflora found to be non-toxic, the purple flower type is highly toxic. The tree's leaves, fruits and flowers can all be consumed - eaten alone as vegetables and added to curries or salads. Known as bok phool in West Bengal, the flower is commonly consumed by dipping in batter and frying. The flowers and leaves are enriched with vitamins and minerals and have been reportedly associated with anti-inflammatory, analgesic and antipyretic effects. A fraction isolated from flowers, preferentially killed leukemic cells in another study.

Leaves of Sesbania grandiflora have the potential to be used as a remedy for thrombosis, diarrhea, and inflammatory diseases and against few important bacterial pathogens [3,4]. The juice of the leaves of $S$. grandiflora has been reportedly used in the treatment of bronchitis, cough, vomiting, wounds ulcers, diarrhea, and dysentery. The flowers have reported antimicrobial activity. Powdered roots of this plant are mixed in water and applied externally as a poultice or rub for rheumatic swelling [5]. The leaves are traditionally used to treat nasal catarrah, nyctalopia and cephalagia. Studies show that, $S$. grandiflora possess antioxidant, antiuroithiatic, anticonvulsive, anti-arthritic, antiinfammatory, anti-helminthic, anti-bacterial and anxiolytic activity [6-8]. Gandhi et.al, 2017 reported that anti-biofilm and antibacterial efficacy of $S$. grandiflora plays a vital role over biofilm producing pathogens and act as a good source for controlling the microbial population [9]. Saifudin et.al, 2016 reported that flower acts as a promising material to develop the active ingredient of anti-plaque toothpaste as well as mouthwash solution [10]. It has been reported that a biofilm is strongly associated with the drug resistance property [11]. Hence, eradication of biofilm is often considered to be a difficult task and therefore use of plant products to inhibit biofilm may be a viable alternative [12]. Ramesh et.al, 2015 showed brain oxidative damage restored by Sesbania grandiflora in cigarette smoke-exposed rats [13]. Earlier, the lead author and associates presented cardioprotective action of $S$. grandiflora aqueous suspension that restored the antioxidant status and retained the levels of micronutrients in cigarette smoke-exposed rats [14,15]. Afterwards, Ramesh et.al, 2010 reported that S. grandiflora aqueous suspension significantly decreased the elevated hepatic, renal and lipid peroxidation markers and ameliorated the diminished antioxidant levels while restored the hepatic and renal architecture in cigarette smoke-exposed rats [16]. Semwal et.al, 2018 reported significant neuroprotective effect in celecoxib treated mice through the modification in cholinergic system or by the blockage of oxidative stress and inhibition of AchE enzyme.at the doses of 200 and $400 \mathrm{mg} / \mathrm{kg}$ in mice [17]. S. grandiflora protects the lung from the oxidative damage through its antioxidant potential [18]. Earlier, Pajaniradje et.al, 2014 reported methanolic fraction of $S$. grandiflora was found to exert potent antiproliferative effects especially in the human lung cancer cell line, A549 [19]. Bhoumik et.al, 2016 reported hepatoprotective activity against $\mathrm{CCl} 4$ induced hepatotoxicity in rats by aqueous extract [20]. Plants contain a huge range of active compounds with the most abundant being polyphenols, carotenoids, vitamin (vitamin A, C, riboflavin, nicotinic acid), and minerals like zinc and selenium which form an integral part of antioxidant systems and reduce cellular damages [21,22]. Roy et.al, 2013 reported that a fraction isolated from flowers, preferentially kills leukemic cells (particularly those of histiocyte lymphoma) by triggering programmed cell death [23]. In 4 different studies from 2012 to 2016, it was found that the flower, fruit and the whole plant extract reduced blood glucose, cholesterol, TG and LDL, lipid peroxidation and increased and superoxide dismutase and catalase of insulin and hemoglobin in experimental animals [24-27]. Afterwards, Prasanna et.al, 2018 demonstrated the hydroxy methoxy benzaldehyde (HMB) content as anti-glycogen lead that inhibited formation of early $\mathrm{HbA} 1 \mathrm{c}$ and advanced glycation end products (AGEs) [28]. The hypoglycemic activity is thought to be due to increased hepatic metabolism followed by stimulation of synthesis and/or release of insulin from pancreatic beta cells and/or insulin sparing effect. High contents of quercetin, myricetin and kaempferol were identified in a methanolic extract of the leaves and a novel protein fraction was isolated from the fresh flowers, which displayed chemo-preventive effects [29,30]. The ethanol extract of the leaves and flowers were effective in inhibiting the tumor growth in ascitic models and that is comparable to 5-Fluorouracil [31]. Chung et.al, 2016 reported that silver nanoparticles (AgNPs) synthesized with leaf extracts were demonstrated to be cytotoxic to MCF-7 cancer cells [32,33]. Moreover, the synthesized AgNPs showed potent antibacterial activity against multi-drug resistant (MDR) bacteria 
such as Salmonella enterica and Staphylococcus aureus [34]. Later on, several studies revealed antimicrobial potential of S. grandiflora synthesized AgNPs [35-40]. Gupta et.al, 2018 revealed antioxidant action of flavonoids especially quercetin and hydroalcoholic extract found to reduce the levels of TNF- $a$ and IL-6 in acetic acid induced ulcerative colitis in mice [41]. Sesbania could afford a significant protective effect against erythromycin estolate-induced hepatotoxicity [42]; alcohol and polyunsaturated fatty acid (PUFA)-induced oxidative stress and nephrotoxicity (due to presence of phenolic compounds and anthocyanins) [43]. Also, the leaf juice of $S$. grandiflora showed significant antiurolithiatic activity against calcium oxalate-type stones in an older study [44]. The fruits are used for anemia, bronchitis, fever, tumors. They are laxative, and possess intellectually stimulating properties [45]. Fruit extract significantly decreased the levels of blood glucose, cholesterol, TG and LDL, lipid peroxidation and increased and superoxide dismutase and catalase in rats [46]. Hasan et.al, 2012 first reported of the four compounds (Isovestitol, medicarpin, sativan and betulinic acid) isolated from the root of $S$. grandiflora and their anti-tuberculosis properties [47]. The bark extract has shown the protective effects against the acute and chronic inflammation $[48,49]$. The bark of $S$. grandiflora is very bitter and considered as an astringent and bitter tonic. Decoctions of leaves and flowers is used to treat leucorrhoea and vomiting of blood. The bark of $S$. grandiflora is used as an astringent and treatment of small pox, ulcers in the mouth and the alimentary canal, infant stomach disorders and scabies [43], [50].

\section{Acknowledgement}

After 3 years of working on 2 publications of Sesbania grandiflora as a co-author, it was very hard to recall many important aspects to be retrieved from memory. However, I'm thankful to Dr. Dr. Jayabrata Das, Associate Professor, Department of Biotechnology, School of Bioengineering, SRM University, Kattankulathur, Chennai, Tamil Nadu, India. for his valuable time to audit my paper and for his thoughtful suggestions. I'm also grateful to seminar library of Faculty of Pharmacy, University of Dhaka and BANSDOC Library, Bangladesh for providing me books, journal and newsletters.

\section{ABBREVIATIONS}

Hydroxy Methoxy Benzaldehyde (HMB); Advanced Glycation End Products (AGEs); Polyunsaturated Fatty Acid (PUFA); Low-density lipoprotein (LDL); Triglyceride (TG); multi-drug resistant (MDR); Silver Nanoparticles (AgNPs); Hemoglobin A1c (HbA1c); Tetrachloromethane (CCl4); Michigan Cancer Foundation-7 (MCF-7); Acetylcholinesterase (AchE)

\section{Financial Disclosure or Funding: N/A}

Conflict of Interest: The author declares that he has no competing interests.

\section{Informed Consent: N/A}

\section{Author contributions: N/A}

\section{References}

1. Tropical Plant Catalog. Available From: toptropicals.com

2. Kapila, S. (2018). Flowers on the menu. Media India (Lifestyle), January 17,.

3. Arfan, N. B., Islam, T., Mohiuddin, A. K., Alam Khan, S., \& Labu, K. (2016). Thrombolytic, membrane stabilizing, antidiarrhoeal, and antimicrobial properties of bioactive compounds isolated from leaves of Sesbania grandiflora naturally growing in Bangladesh. Iranian Journal of Pharmaceutical Sciences, 12(3), 31-46.

4. Arfan, N. B., Islam, T., Mohiuddin, A. K., Alam Khan, S., \& Labu, K. (2016). Ibnosina J Med BS, 8(6), 271-277.

5. Aye, M. M., Aung, H. T., Sein, M. M., \& Armijos, C. (2019). A Review on the Phytochemistry, Medicinal Properties and Pharmacological Activities of 15 Selected Myanmar Medicinal Plants. Molecules, 24(2), 293.

6. Gomase, P. V. (2012). Sesbania sesban Linn: a review on its ethnobotany, phytochemical and pharmacological profile. Asian journal of biomedical and pharmaceutical sciences, 2(12), 11.

7. China, R., Mukherjee, S., Sen, S., Bose, S., Datta, S., Koley, H., ... \& Dhar, P. (2012). Antimicrobial activity of Sesbania grandiflora flower polyphenol extracts on some pathogenic bacteria and growth stimulatory effect on the probiotic organism Lactobacillus acidophilus. Microbiological research, 167(8), 500-506.

8. Rajagopal, P. L., Premaletha, K., \& Sreejith, K. R. (2016). Anthelmintic activity of the flowers of Sesbania grandiflora Pers. Journal of Innovations in Applied Pharmaceutical Sciences, 1(2), 8-11.

9. Gandhi, A. D., Vizhi, D. K., Lavanya, K., Kalpana, V. N., Rajeswari, V. D., \& Babujanarthanam, R. (2017). In vitro anti-biofilm and anti-bacterial activity of Sesbania grandiflora extract against Staphylococcus aureus. Biochemistry and biophysics reports, 12 , 193-197.

10. Saifudin, A., Forentin, A. M., Fadhilah, A., Tirtodiharjo, K., Melani, W. D., Widyasari, D., \& Saroso, T. A. (2016). Bioprospecting for anti-Streptococcus mutans: The activity of $10 \%$ Sesbania grandiflora flower extract comparable to erythromycin. Asian Pacific Journal of Tropical Biomedicine, 6(9), 751-754.

11. Arun, A., Karthikeyan, P., Sagadevan, P., Umamaheswari, R., \& Peo, R. R. (2014). Phytochemical screening of Sesbania grandiflora (Linn). Int J Biosci Nanosci, 1(2), 33-36. 
12. Das, A., Das, M. C., Sandhu, P., Das, N., Tribedi, P., De, U. C., ... \& Bhattacharjee, S. (2017). Antibiofilm activity of Parkia javanica against Pseudomonas aeruginosa: a study with fruit extract. RSC Advances, 7(9), 5497-5513.

13. Ramesh, T., Sureka, C., Bhuvana, S., Begum, .VH.( 2015). Brain oxidative damage restored by Sesbania grandiflora in cigarette smoke-exposed rats. Metab Brain Dis, 30(4), 959-68.

14. Ramesh, T., Mahesh, R., Sureka, C., Begum, V.H. (2008). Cardioprotective effects of Sesbania grandiflora in cigarette smokeexposed rats. J Cardiovasc Pharmacol, 52(4), 338-43.

15. Shah, S.M.A., Akram, M., Riaz, M., Munir, N., Rasool, G.( 2019). Cardioprotective Potential of Plant-Derived Molecules: A Scientific and Medicinal Approach. Dose Response, 17(2),

16. Ramesh, T., Sureka, C., Bhuvana, S., Hazeena, B. V.( 2010). Sesbania grandiflora diminishes oxidative stress and ameliorates antioxidant capacity in liver and kidney of rats exposed to cigarette smoke. J Physiol Pharmacol, 61(4),467-76.

17. Semwal, B.C, Murti, Y., Verma, M., Yadav, HN.( 2018). Neuroprotective Activity of Semba - Nia grandiflora Seeds Extract Against Celecoxib Induced Amnesia in Mice. Pharma cog J, 10(4),747-52

18. Bhoumik, D., Mallik, A., \& Berhe, A. H. (2016). Hepatoprotective activity of aqueous extract of Sesbania grandiflora Linn leaves against carbon tetrachloride induced hepatotoxicity in albino rats. Int J Phytomed, 8(2), 294-299.

19. Pajaniradje, S., Mohankumar, K., Pamidimukkala, R., Subramanian, S., \& Rajagopalan, R. (2014). Antiproliferative and apoptotic effects of Sesbania grandiflora leaves in human cancer cells. BioMed research international, 2014.

20. Ramesh, T., \& Begum, V. H. (2008). Protective effect of Sesbania grandiflora against cigarette smoke-induced oxidative damage in rats. Journal of medicinal food, 11(2), 369-375.

21. Zarena, A. S., Gopal, S., \& Vineeth, R. (2014). Antioxidant, antibacterial, and cytoprotective activity of agathi leaf protein. Journal of analytical methods in chemistry, 2014.

22. Velusamy, P., Kumar, G. V., Jeyanthi, V., Das, J., \& Pachaiappan, R. (2016). Bio-inspired green nanoparticles: synthesis mechanism, and antibacterial application. Toxicological research, 32(2), 95.

23. Roy, R., Kumar, D., Chakraborty, B., Chowdhury, C., \& Das, P. (2013). Apoptotic and autophagic effects of Sesbania grandiflora flowers in human leukemic cells. PLoS One, 8(8), e71672.

24. Kumar, R., Janadri, S., Kumar, S., \& Swamy, S. (2015). Evaluation of antidiabetic activity of alcoholic extract of flower Sesbania grandiflorain alloxan induced diabetic rats. Asian Journal of Pharmacy and Pharmacology, 1(1), 21-26.

25. Panigrahi, G., Panda, C., Mishra, U. S., Mahapatra, S., Pasa, G., \& Acharya, A. K. (2012). Investigation of possible hypoglycemic and hypolipidemic effect of methanolic extract of Sesbania grandiflora. International research journal of pharmacy, 3(5), 275-280.

26. Ghanshyam, P., Panda, C., Patra, A. (2016).Extract of Sesbania grandiflora Ameliorates Hyperglycemia in High Fat DietStreptozotocin Induced Experimental Diabetes Mellitus. Scientifica (Cairo), 4083568.

27. Sureka, C., Ramesh, T., \& Begum, V. H. (2015). Attenuation of erythrocyte membrane oxidative stress by Sesbania grandiflora in streptozotocin-induced diabetic rats. Biochemistry and Cell Biology, 93(4), 385-395.

28. Prasanna, G., Har,i N., Saraswathi, N.T. (2018) Hydroxy methoxy benzaldehyde from Sesbania grandilfora inhibits the advanced glycation end products (AGEs)-mediated fibrillation in hemoglobin. J Biomol Struct Dyn, 36(4), 819-829.

29. Sangeetha, A., Prasath, G.S., Subramanian, S. (2014) Antihyperglycemic and antioxidant potentials of Sesbania grandiflora leaves studied in STZ induced experimental diabetic rats. Int J Pharm Sci Res, 5(6), 2266-75.

30. Mustafa, R. A., Hamid, A. A., Mohamed, S., \& Bakar, F. A. (2010). Total phenolic compounds, flavonoids, and radical scavenging activity of 21 selected tropical plants. Journal of food science, 75(1), C28-C35.

31. Laladhas, K. P., Cheriyan, V. T., Puliappadamba, V. T., Bava, S. V., Unnithan, R. G., Vijayammal, P. L., \& Anto, R. J. (2010). A novel protein fraction from Sesbania grandiflora shows potential anticancer and chemopreventive efficacy, in vitro and in vivo. Journal of Cellular and Molecular Medicine, 14(3), 636-646.

32. Chung, I. M., Park, I., Seung-Hyun, K., Thiruvengadam, M., \& Rajakumar, G. (2016). Plant-mediated synthesis of silver nanoparticles: their characteristic properties and therapeutic applications. Nanoscale research letters, 11(1), 40.

33. Lalitha, P. (2015). Apoptotic efficacy of biogenic silver nanoparticles on human breast cancer MCF-7 cell lines. Progress in biomaterials, 4(2-4), 113-121.

34. Das, J., Das, M. P., \& Velusamy, P. (2013). Sesbania grandiflora leaf extract mediated green synthesis of antibacterial silver nanoparticles against selected human pathogens. Spectrochimica Acta Part A: Molecular and Biomolecular Spectroscopy, 104, 265-270.

35. Jeyaraj, M., Sathishkumar, G., Sivanandhan, G., MubarakAli, D., Rajesh, M., Arun, R., ... \& Ganapathi, A. (2013). Biogenic silver nanoparticles for cancer treatment: an experimental report. Colloids and surfaces B: Biointerfaces, 106, 86-92.

36. Ajitha, B., Reddy, Y. A. K., Rajesh, K. M., \& Reddy, P. S. (2016). Sesbania grandiflora leaf extract assisted green synthesis of silver nanoparticles: Antimicrobial activity. Materials Today: Proceedings, 3(6), 1977-1984.

37. Venkatesan, J., Kim, S. K., \& Shim, M. (2016). Antimicrobial, antioxidant, and anticancer activities of biosynthesized silver nanoparticles using marine algae Ecklonia cava. Nanomaterials, 6(12), 235.

38. Firdhouse, M. J., \& Lalitha, P. (2013). Biosynthesis of silver nanoparticles using the extract of Alternanthera sessilisantiproliferative effect against prostate cancer cells. Cancer nanotechnology, 4(6), 137.

39. Otunola, G. A., \& Afolayan, A. J. (2018). In vitro antibacterial, antioxidant and toxicity profile of silver nanoparticles greensynthesized and characterized from aqueous extract of a spice blend formulation. Biotechnology \& Biotechnological Equipment, 32(3), 724-733. 
40. Hembram, K. C., Kumar, R., Kandha, L., Parhi, P. K., Kundu, C. N., \& Bindhani, B. K. (2018). Therapeutic prospective of plantinduced silver nanoparticles: application as antimicrobial and anticancer agent. Artificial cells, nanomedicine, and biotechnology, 46(sup3), S38-S51.

41. Sreelatha, S., Padma, P. R., \& Umasankari, E. (2011). Evaluation of anticancer activity of ethanol extract of Sesbania grandiflora (Agati Sesban) against Ehrlich ascites carcinoma in Swiss albino mice. Journal of ethnopharmacology, 134(3), 984-987.

42. Gupta, R. A., Motiwala, M. N., Mahajan, U. N., \& Sabre, S. G. (2018). Protective effect of Sesbania grandiflora on acetic acid induced ulcerative colitis in mice by inhibition of TNF-a and IL-6. Journal of ethnopharmacology, 219, 222-232..

43. Pari, L., \& Uma, A. (2003). Protective effect of Sesbania grandiflora against erythromycin estolate-induced hepatotoxicity. Therapie, 58(5), 439-443..

44. Doddola, S., Pasupulati, H., Koganti, B., \& Prasad, K. V. (2008). Evaluation of Sesbania grandiflora for antiurolithiatic and antioxidant properties. Journal of natural medicines, 62(3), 300-307.

45. Kumaravel, M., Karthiga, K., Raviteja, V., \& Rukkumani, R. (2011). Protective effects of Sesbania grandiflora on kidney during alcohol and polyunsaturated fatty acid-induced oxidative stress. Toxicology mechanisms and methods, 21(5), 418-425.

46. Lakshmi, T. (2011). Hadga (Sesbania Grandiflora Linn.)-A Unique Ayurvedic Remedy. Int. J. Drug Dev. Res, 3(4), 1-3.

47. Hasan, N., Osman, H., Mohamad, S., Chong, W. K., Awang, K., \& Zahariluddin, A. S. M. (2012). The chemical components of Sesbania grandiflora root and their antituberculosis activity. Pharmaceuticals, 5(8), 882-889.

48. Patil, R. B., Nanjwade, B. K., \& Manvi, F. V. (2010). Effect of Sesbania grandiflora and Sesbania sesban bark on carrageenan induced acute inflammation and adjuvant-induced arthritis in rats. Pharma Science Monitor, 1(1), 75-89.

49. Srivastava, S., Singh, P., Jha, K. K., Mishra, G., Srivastava, S., \& Khosa, R. L. (2012). Evaluation of anti-arthritic potential of the methanolic extract of the aerial parts of Costus speciosus. Journal of Ayurveda and integrative medicine, 3(4), 204.

50. Munde-Wagh, K. B., Wagh, V. D., Toshniwal, S. S., \& Sonawane, B. R. (2012). Phytochemical, antimicrobial evaluation and determination of total phenolic and flavonoid contents of Sesbania grandiflora flower extract. Int. J. Pharm. Sci, 4(4), $229-232$. 